\title{
A Low-Profile and Compact Split-Ring Antenna with Horizontally Polarized Omnidirectional Radiation
}

\author{
Kittima Lertsakwimarn, ${ }^{1}$ Chuwong Phongcharoenpanich, ${ }^{1}$ and Takeshi Fukusako ${ }^{2}$ \\ ${ }^{1}$ Faculty of Engineering, King Mongkut's Institute of Technology Ladkrabang, 1, Chalongkrung Road, Ladkrabang, \\ Bangkok 10520, Thailand \\ ${ }^{2}$ Graduate School of Science and Technology, Kumamoto University, 2-39-1 Kurokami, Chuo-ku, Kumamoto 860-8555, Japan
}

Correspondence should be addressed to Kittima Lertsakwimarn; wimand.mai@gmail.com

Received 25 August 2014; Accepted 22 October 2014

Academic Editor: Guo Qing Luo

Copyright (C) 2015 Kittima Lertsakwimarn et al. This is an open access article distributed under the Creative Commons Attribution License, which permits unrestricted use, distribution, and reproduction in any medium, provided the original work is properly cited.

\begin{abstract}
This paper presents a low-profile and compact printed antenna having an omnidirectional radiation pattern with horizontal polarization to the ground. The proposed antenna consists of an inner small fed ring, an outer coupled split ring, and a ground plane. The overall dimension of the proposed antenna is $45 \mathrm{~mm} \times 50.5 \mathrm{~mm} \times 11.6 \mathrm{~mm}\left(0.138 \lambda_{0} \times 0.155 \lambda_{0} \times 0.036 \lambda_{0}\right)$. The -10 - $\mathrm{dB}$ $\left|S_{11}\right|$ of the antenna covers the $920-\mathrm{MHz}$ RFID band, and the gain is about $1.45 \mathrm{dBi}$ in the parallel direction to the ground plane. The measured results show good agreements with the simulated results. Furthermore, the reasons for the low-profile structure and the omnidirectional radiation pattern are also discussed.
\end{abstract}

\section{Introduction}

Antennas with horizontally polarized omnidirectional radiation pattern in the azimuth plane can be applied to many applications such as base stations and wireless communications. Such antennas are useful for, especially, polarization diversity being combined with vertically polarized omnidirectional antennas. The Alford loop antenna in the wire type was firstly reported to achieve an omnidirectional horizontal polarization [1]. Several modifications of the Alford loop antenna have been presented in $[2,3]$. Other techniques for achieving omnidirectional pattern and horizontal polarization have also been studied. For example, four flag-shaped radiators are connected to four tapered strip lines terminated with a small circular patch at the centers on both sides of a substrate [4]. A series-fed array of loop antennas, which consists of four $\mu$-negative transmission lines (MNG-TL), was presented in [5]. However, many wireless devices require compact and light weight antenna elements with a low-profile structure [6].

Low-profile antennas installed on a back conductor can effectively reduce the electrical effect from backing material such as IC-chip, electrical circuits, and coupling with other antennas [7]. Many low-profile antennas, such as disk loaded monopoles, tend to be vertically polarized radiations [611]. In [6], a loop structure can be miniaturized by using inductors. A loop-shaped inverted-F wire antenna (LIFA) has been presented in [9]. In [10], a vertically polarized cavity-backed composite slot loop antenna (CBCSLA) with omnidirectional radiation in the horizontal plane having extremely small height is presented. An inductively coupled capacitively loaded monopole antenna (ICCLMA) consisting of two metal layers, a feeding pin, and a shorting pin has been presented for achieving a high-gain, low-profile, and miniaturized characteristics with vertically polarized omnidirectional radiation [11]. In [8], a folded monopole antenna with capacitively coupled parasitic elements in the same plane is studied. However, as far as the authors know, no research has studied the compact and low-profile antenna having horizontally polarized omnidirectional radiation pattern.

Small antennas such as short dipoles or small loops have usually small resistance and large reactance components in impedance. Therefore, it is difficult for such antennas to be matched to the required impedance such as $50 \Omega$ [12]. Several small antennas with impedance matching techniques have been reported considering the above situations of 


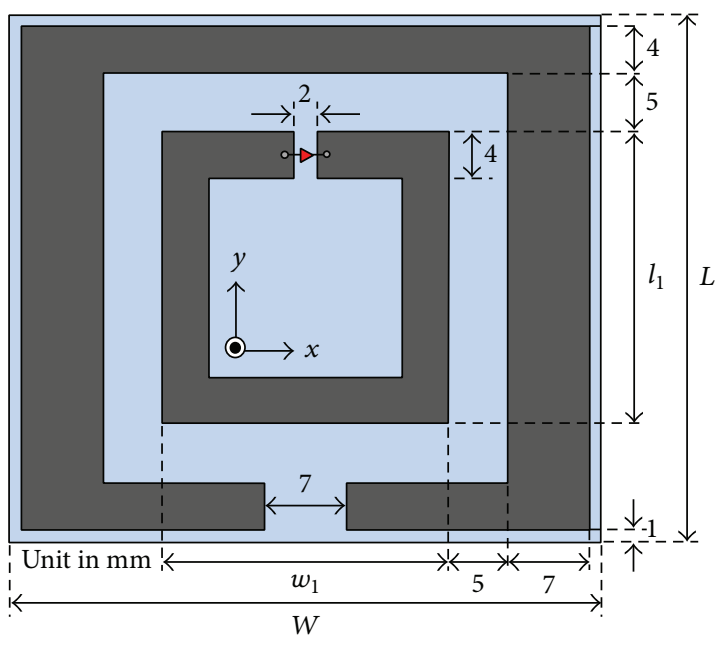

(a)

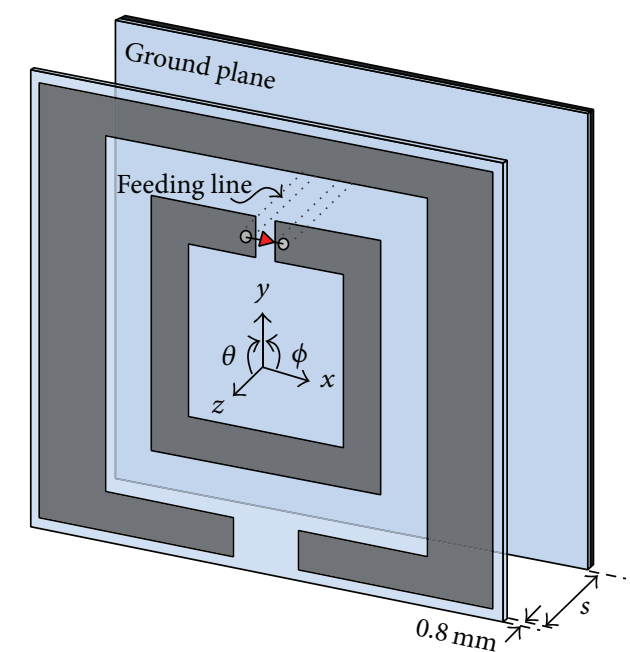

(b)

FIGURE 1: Geometry of the proposed antenna with ground plane: (a) front view and (b) perspective view.

impedance. A small loop antenna is a simple structure to achieve horizontally polarized omnidirectional radiation pattern with a uniform current distribution acting as a magnetic dipole. However, it is still faced with a difficulty in impedance matching because the small loop has small radiation resistance and large reactance $[5,13]$. For solving this problem, printed split-ring antennas (SRAs) consisting of a small inner fed ring and an outer coupled split ring element are presented to match the impedance [14-16]. However, these antennas have neither a ground plane nor a backing conductor.

In this paper, a compact, planar, and low-profile SRA having a ground plane is proposed for radiating horizontal polarization in omnidirection. With the advantages of lowprofile structure, a low-profile polarization diversity antenna can be achieved by combining the SRA with a low-profile vertically polarized monopole antenna for base station and RFID reader applications [17]. The performances of SRA with and without ground plane are demonstrated, and the mechanisms for the performances are also explained by observing the electric field (e-field) distribution.

\section{Antenna Structure}

The proposed antennas are designed and simulated using the CST MW Studio [18] throughout this paper. Figure 1 shows the proposed antenna structure consisting of a substrate, parallel feeding lines, and a ground plane. On the substrate, a fed inner ring and a coupled outer split ring are printed on a dielectric substrate of Arlon Diclad522 $\left(\varepsilon_{r}=2.6, \tan \delta=\right.$ $\left.2.0 \times 10^{-4}\right)$ with $0.8 \mathrm{~mm}$ thickness. The dimensions are $45 \mathrm{~mm}$ $\left(0.138 \lambda_{0}\right)$ in length $(L)$ and $50.5 \mathrm{~mm}\left(0.155 \lambda_{0}\right)$ in width $(W)$. The length and width of the inner and outer rings are optimized so as to resonate at the UHF RFID band around $920 \mathrm{MHz}$. The dimensions of the proposed antenna with and without ground plane are shown in Table 1. The SRA structure can reduce the overall size of the antenna because
TABLE 1: The structural parameters.

\begin{tabular}{lcc}
\hline Parameter & Without GND & With GND \\
\hline$W$ & $50.0 \mathrm{~mm}$ & $50.5 \mathrm{~mm}$ \\
$L$ & $45.5 \mathrm{~mm}$ & $45.0 \mathrm{~mm}$ \\
$w_{1}$ & $24.0 \mathrm{~mm}$ & $25.0 \mathrm{~mm}$ \\
$l_{1}$ & $25.5 \mathrm{~mm}$ & $24.5 \mathrm{~mm}$ \\
\hline
\end{tabular}

the capacitive coupling between the two rings makes the resonance at a low frequency $[7,19]$. In Figure 1, a ground plane with the same size as the substrate has been installed. The air interval $s$ between the substrate and ground plane is chosen as $10 \mathrm{~mm}\left(0.036 \lambda_{0}\right)$ as shown in Figure $1(\mathrm{~b})$ considering the impedance matching. When $s>10 \mathrm{~mm}$ having the ground plane with the same dimension as the upper element substrate, the impedance bandwidth is narrower than $15 \mathrm{MHz}$, which is a sufficient value for some applications such as RFID and mobile telecommunications. The effects of variation in the size of ground plane and the air interval will be discussed in Section 5. In addition, we can sufficiently regard the antenna with $s=10 \mathrm{~mm}$ as low profile. Furthermore, we can make sure that the vertical component is suppressed in such a situation that the vertical component may be easily radiated. Photographs of the fabricated antennas are shown in Figure 2. Since the ground plane of the antenna is small, a bazooka balun has been equipped to suppress the leakage current on the coaxial cable.

\section{Results and Discussions}

3.1. Antenna without Ground Plane. In this section, an SRA without the ground plane is considered with almost the same dimensions as shown in Table 1. The antenna is fed through the bazooka balun because the feeding point should be balanced. Figure 3 shows the simulated and measured results of $\left|S_{11}\right|$. The simulated and measured $-10-\mathrm{dB}\left|S_{11}\right|$ 

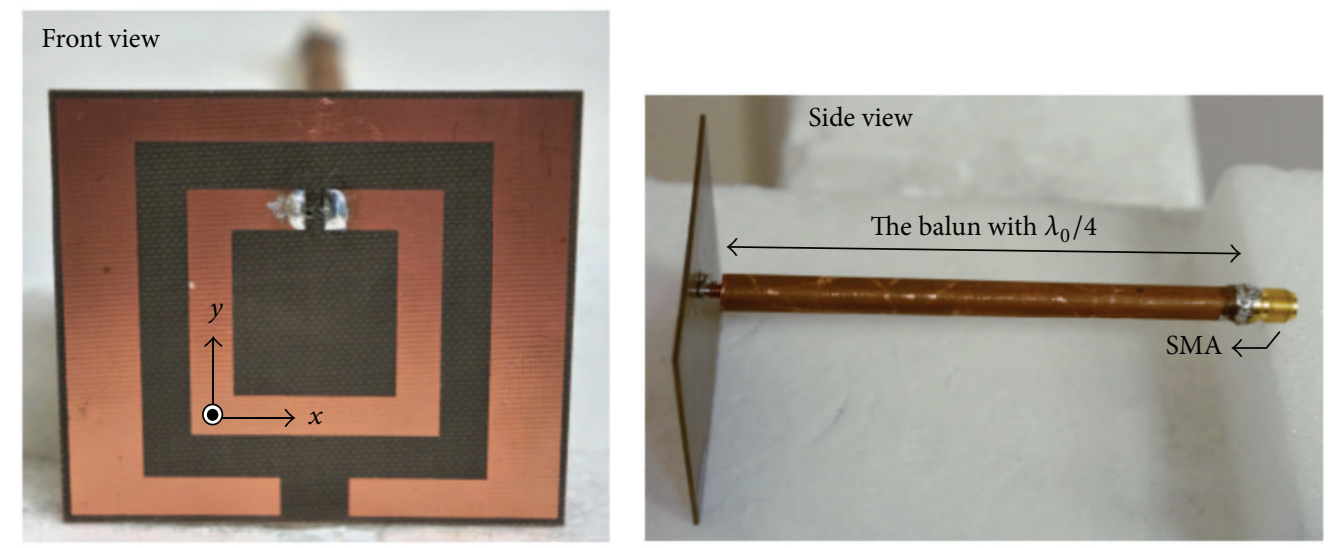

(a)
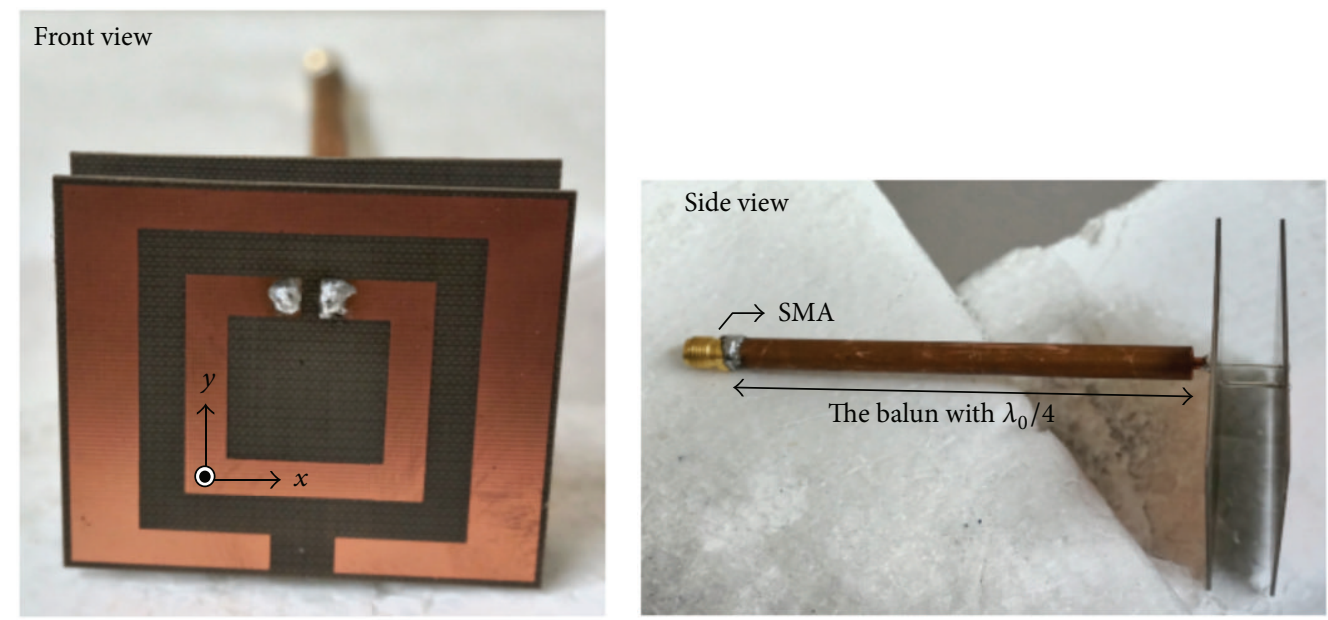

(b)

FIGURE 2: Photograph of fabricated prototype antenna (a) without ground plane and (b) with ground plane in perspective views and side views. Each structure has the feeding cable and the balun.

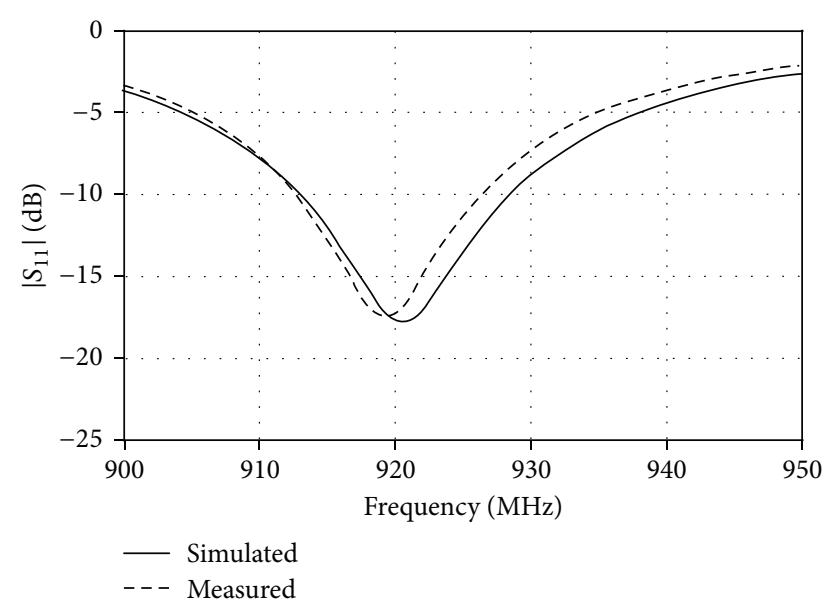

FIgURE 3: Simulated and measured $\left|S_{11}\right|$ characteristics.

bands can cover the UHF RFID band (920-925 MHz) with $1.5 \%$ and $1.3 \%$ bandwidth, respectively.

Figure 4 shows the simulated and measured radiation patterns of $E_{\phi}$ and $E_{\theta}$ in the $x-y, y-z$, and $x-z$ planes at
$920 \mathrm{MHz}$. The simulated and measured cross-polarizations of $E_{\theta}$ are lower by $20 \mathrm{~dB}$ than the co-polarizations of $E_{\phi}$ in omnidirection of the $x-y$ and $y-z$ planes and has the maximum gain of $1.7 \mathrm{dBi}$ along the $+y$-direction at $920 \mathrm{MHz}$. The antenna provides nearly omnidirectional patterns in these two planes.

3.2. Antenna with Ground Plane. The ground plane with the same size as the upper substrate is installed. The simulated and measured results of $\left|S_{11}\right|$ are shown in Figure 5. Comparing Figure 5 with Figure 3, the simulated and measured bandwidth is decreased by $0.5 \%$ each after installing the ground plane. The simulated and measured gains along $+y$ direction at $920 \mathrm{MHz}$ are $1.45 \mathrm{dBi}$ and $1.1 \mathrm{dBi}$, respectively, and the radiation efficiency is $99 \%$. However, as shown in Figure 6, the polarization and the radiation patterns are unchanged essentially from the pattern in Figure 4 as far as using this size of ground plane. Polarization is still parallel to the substrate and ground, and the radiation pattern is still omnidirectional. Moreover, the ground plane has only a small effect on the antenna gain. The mechanisms for obtaining the results can be explained from the e-field distributions in the next section. 


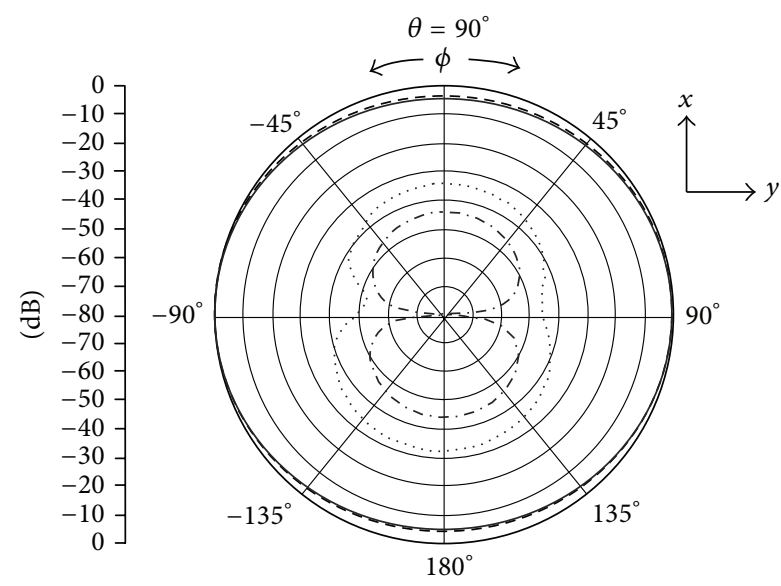

(a)

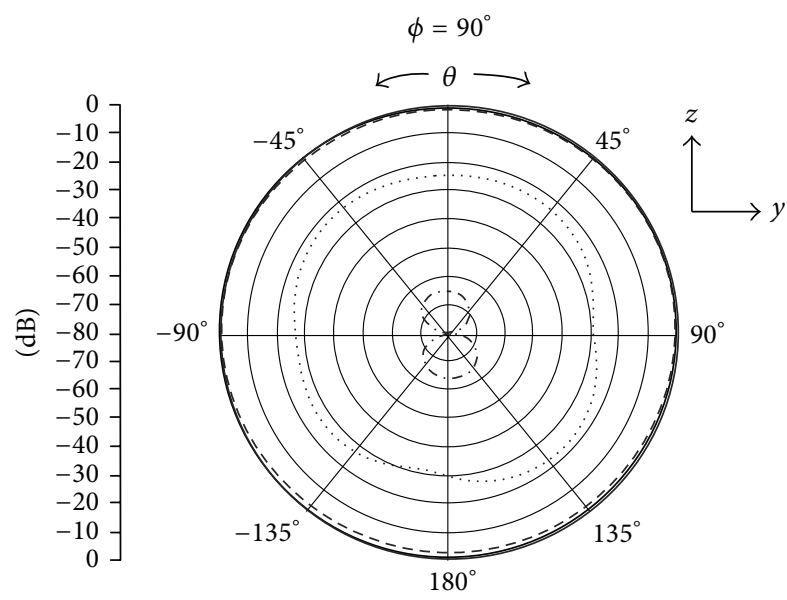

(b)

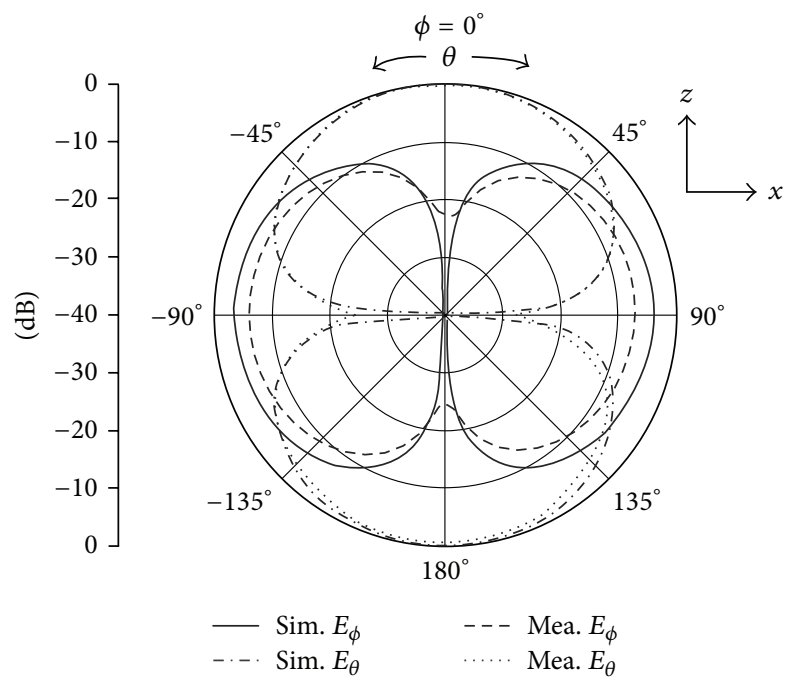

(c)

FIGURE 4: Radiation patterns at $920 \mathrm{MHz}$ in the (a) $x-y$ plane, (b) $y-z$ plane, and (c) $x-z$ plane.

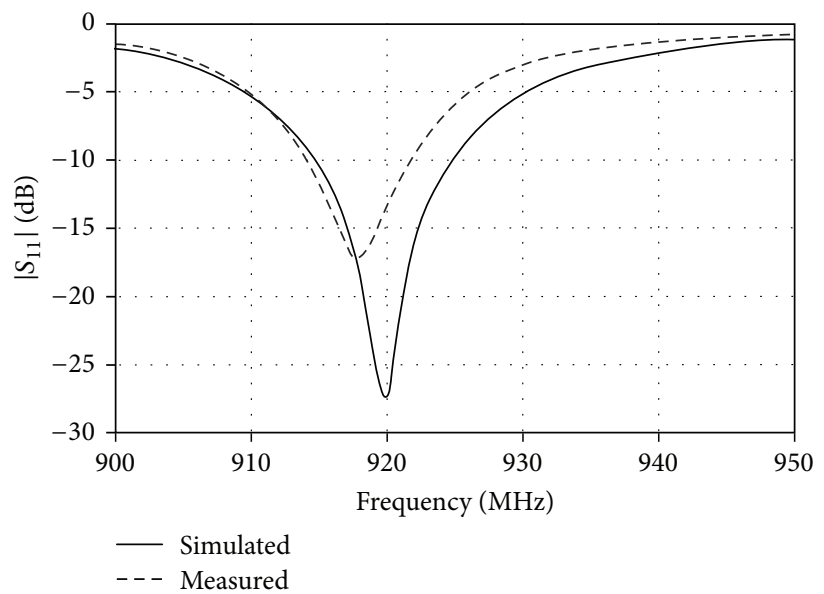

FIGURE 5: Simulated and measured $\left|S_{11}\right|$ characteristics. 


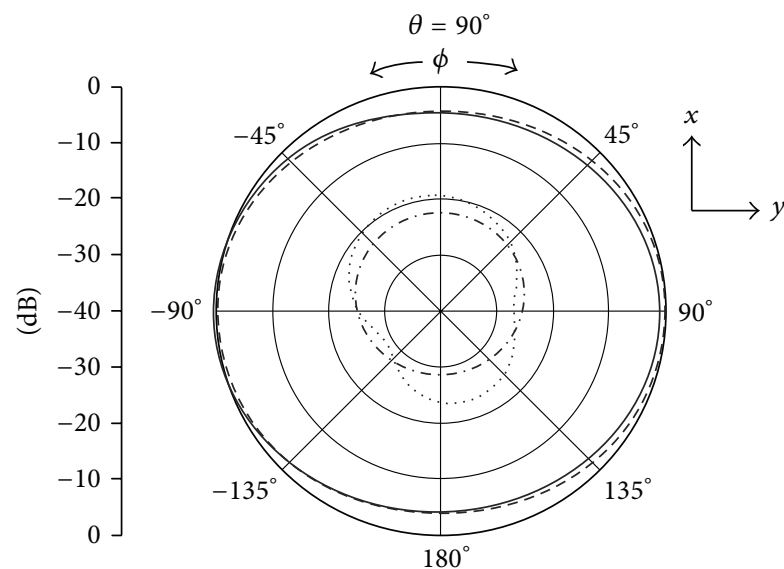

(a)

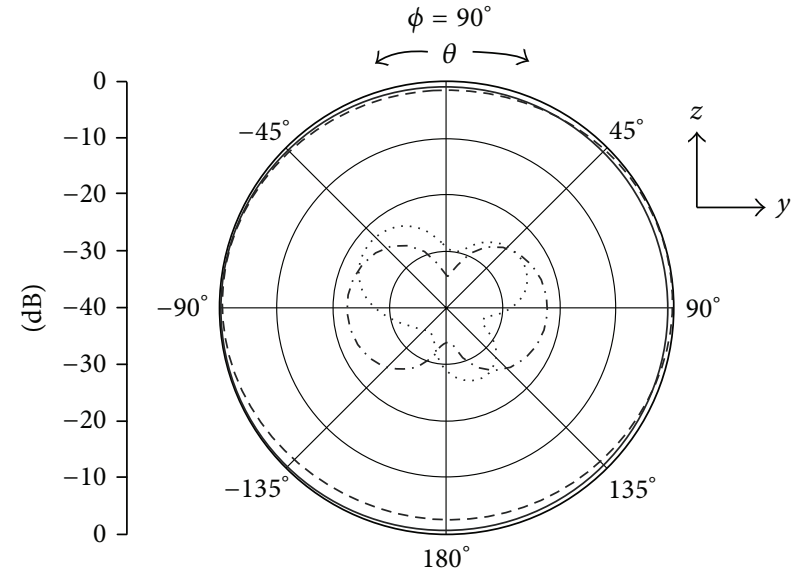

(b)

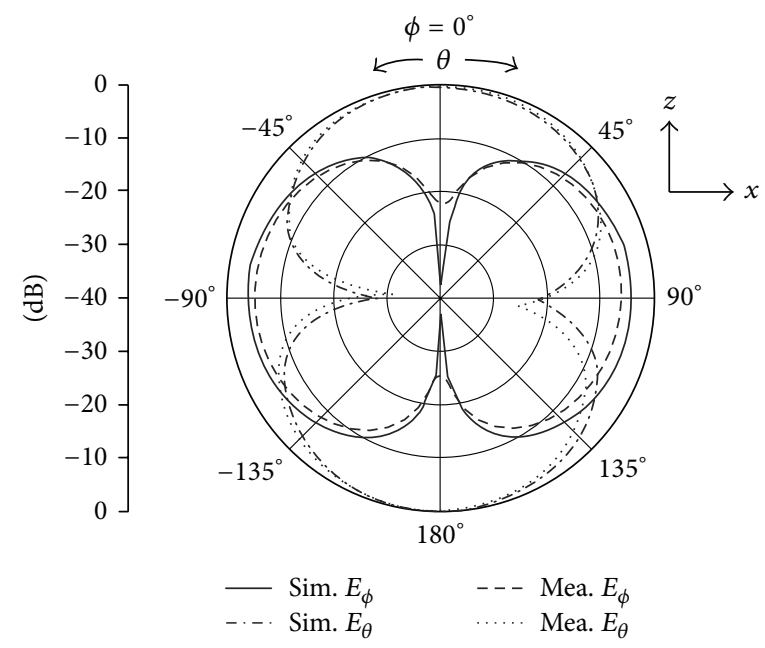

(c)

FIGURE 6: Radiation patterns at $920 \mathrm{MHz}$ in the (a) $x-y$ plane, (b) $y-z$ plane, and (c) $x-z$ plane.

\section{Radiation Mechanism of Horizontally Polarized Omnidirectional Radiation Pattern}

The radiation mechanism of horizontal polarization from the low-profile antenna is discussed in this section. From the results in Section 3, the proposed antennas with and without ground plane can radiate horizontal polarization to the ground or substrate. The mechanisms for the behavior are explained by discussing the distributions of e-field. The e-field distributions of the SRA without the ground plane in the $x-y$ plane are shown in Figure 7 at $\omega t=0^{\circ}$ and $90^{\circ}$, where the voltage at the feeding point is assumed to be $V=V_{0} \sin$ $\omega t$. For $\omega t=0^{\circ}$, the e-field distribution on the SRA structure shows weak strength as shown in Figure 7(a). At $\omega t=90^{\circ}$, the strongest e-field distribution can be found around in the two rings of the antenna. Many of the e-field vectors are parallel to $x$-direction as shown in Figure 7(b).

Next, the SRA structure with the ground plane is discussed. Figure 8 shows the e-field distribution in the $x-y$ plane at $\omega t=0^{\circ}$ and $90^{\circ}$. At $\omega t=0^{\circ}$, the e-field shows asymmetric distribution to the $y-z$ plane but the strength is weak. At $\omega t=90^{\circ}$, similar e-field distribution to that in Figure 7 can be observed as shown in Figure 8(b).

From the results, the antenna can radiate horizontal polarization either with or without the ground plane. Figure 9 shows the e-field distributions in the $x-z$ plane at distances of $20 \mathrm{~mm}$ from the center of substrate along the $y$-axis at $\omega t=0^{\circ}$ and $90^{\circ}$. At $\omega t=0^{\circ}$, the e-field distribution is very weak as shown in Figure 9(a). At $\omega t=90^{\circ}$, the e-field strength is symmetrical about the $y-z$ plane at the center of the ground, and the vertical $z$-components to the ground plane is mainly observed. Each e-field distribution in the left- or right-half part in Figure 9 has the opposite direction to the e-field in the other part. This results in canceling the radiation of vertical $z$ component in the far field. Therefore, the low-profile antenna can radiate horizontal polarization to the ground plane, even if the ground plane is installed.

The omnidirectional radiation pattern can be explained by the e-field distribution in the $x-y$ plane at $\omega t=90^{\circ}$ as shown in Figure 10. The e-field behavior is explained here 


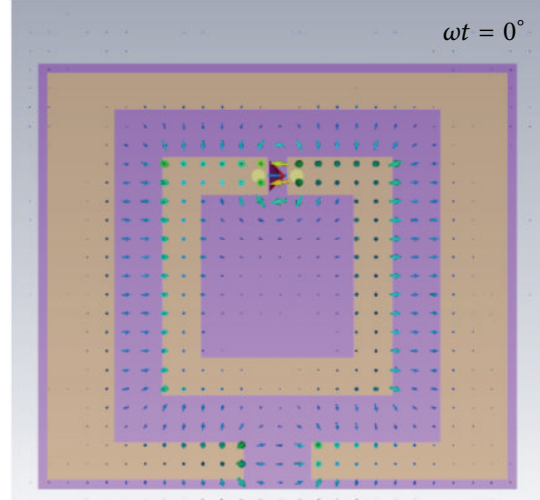

(a)

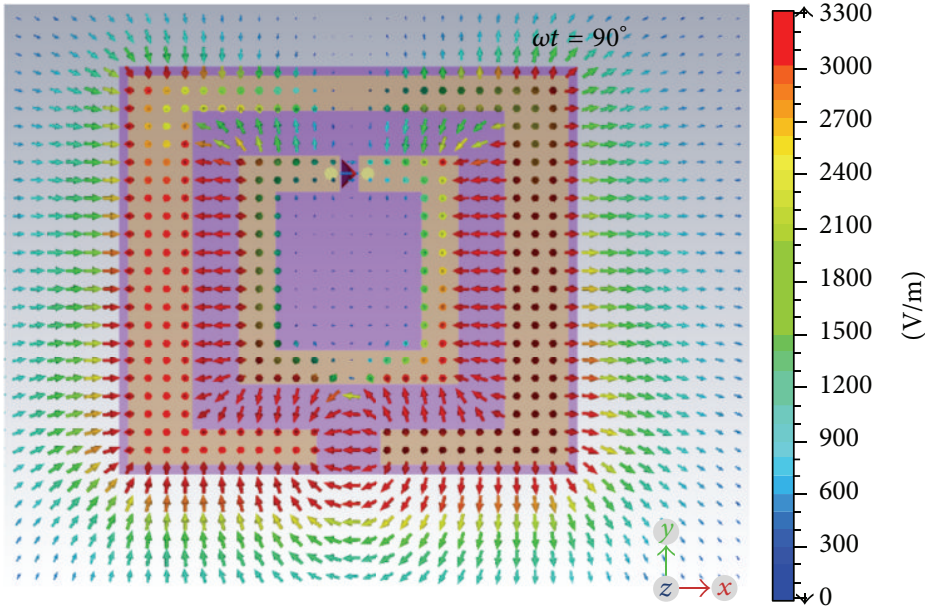

(b)

FIGURE 7: Electric field distributions of the antenna without ground plane in the $x-y$ plane on the element surface at $920 \mathrm{MHz}$ with (a) $\omega t=0^{\circ}$ and (b) $\omega t=90^{\circ}$.

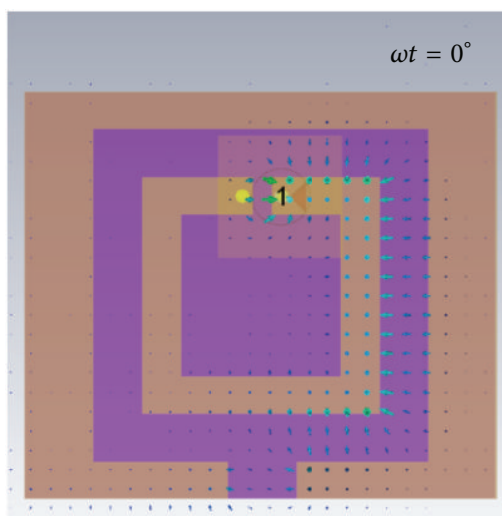

(a)

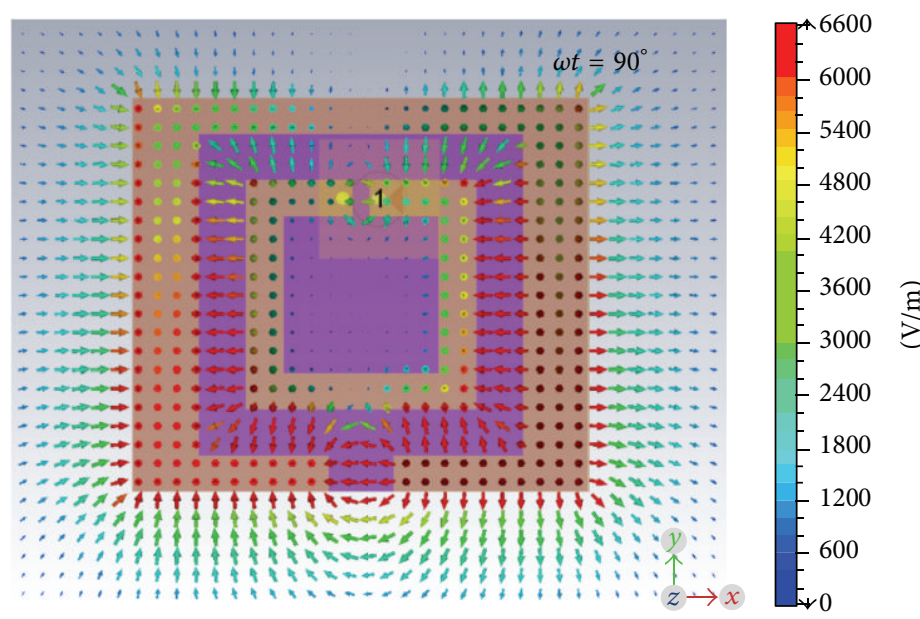

(b)

FIGURE 8: Electric field distributions of the antenna with ground plane in the $x-y$ plane on the element surface at $920 \mathrm{MHz}$ with (a) $\omega t=0^{\circ}$ and (b) $\omega t=90^{\circ}$.

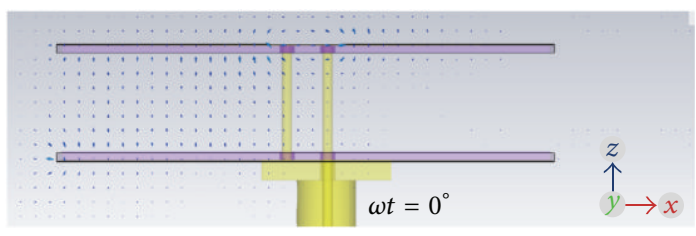

(a)

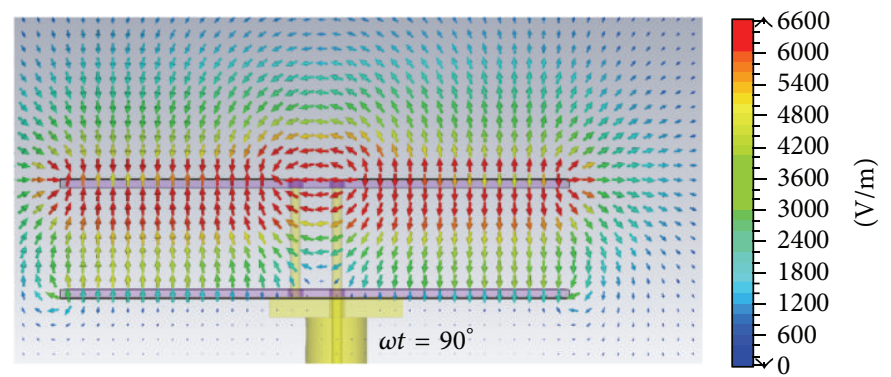

(b)

FiguRE 9: Electric field distribution in the $x-z$ plane at a distance of $20 \mathrm{~mm}$ from the center of substrate along the $y$-axis (a) at $\omega t=0^{\circ}$ and (b) at $\omega t=90^{\circ}$. 


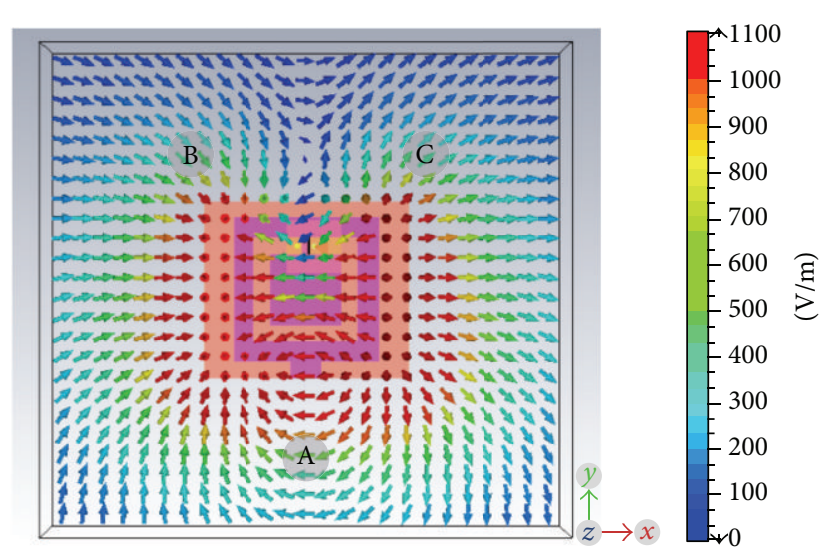

FIGURE 10: Electric field distribution in the $x-y$ plane at a distance of $7 \mathrm{~mm}$ above the surface of the upper substrate at $\omega t=90^{\circ}$.

using the points $\mathrm{A}, \mathrm{B}$, and $\mathrm{C}$ in the figure. At the point $\mathrm{A}$, strong e-field distribution directed parallel to $x$-direction is observed. The e-field at point $\mathrm{B}$ goes into the antenna element, and the e-field at $\mathrm{C}$ goes out of the element. The e-fields at points $\mathrm{B}$ and $\mathrm{C}$ are continuously connected in the far region. Given the fact that e-field is always continuous at a boundary, we can understand that the e-field distribution in Figure 10 has a continuous distribution in the far region surrounding the antenna. Considering the behaviors of efield at the points $\mathrm{A}, \mathrm{B}$, and $\mathrm{C}$, the e-field finally forms a vortex-like e-field distribution which is parallel to the $x-y$ plane at $\omega t=90^{\circ}$; however, showing such distribution in farther region is difficult because the simulating computer has an insufficient memory size. As a result, we can understand that the proposed antenna can have the horizontally polarized omnidirectional radiation pattern.

Similarly, we can observe the other omnidirectional radiation pattern in the $y$ - $z$ plane. As seen in the Figures 8 and 10 , we can find that the e-field is parallel to $x$ direction around the antenna. On the other hand, as discussed with Figure 9, the radiation of e-field directed to $\pm z$-directions is cancelled in the far field. These behaviors contribute to radiating the omnidirectional pattern in the $y$ - $z$ plane.

\section{Effects of Structural Parameters}

The proposed antenna has low-profile structure and horizontal polarization to the ground plane. This section discusses the effects on the antenna performance of the ground plane size and the air interval between the substrate and the ground plane.

5.1. Effects of Ground Plane Size. The effect of the ground plane size is discussed. The ground plane is extended in all directions in the $x-y$ plane by parameter $g$ as shown in Figure 11. The simulated input impedance characteristics and $\left|S_{11}\right|$ as a function of $g$ are shown in Figure 12. From the results in Figure 12(a), the kink size gets gradually magnified when expanding $g$. As a result, we can see that the

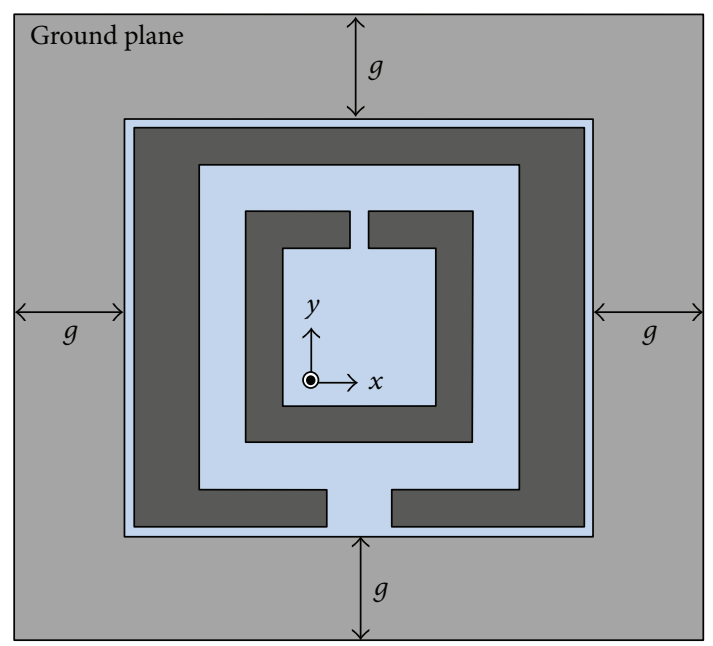

FIGURE 11: Direction of extension parameter $g$.

ground plane size is affecting the impedance of the proposed antenna.

The simulated radiation patterns in the $y-z$ plane at the respective resonant frequencies with several $g$ values are shown in Figure 13. With an increase in $g$ from 0 to $40 \mathrm{~mm}$, the radiation pattern becomes bidirectional pattern when $g=40 \mathrm{~mm}$ as shown in Figure 13(a). At the same time, the cross-polarization in $\pm z$-direction $\left(\phi=90^{\circ}, \theta=0^{\circ}, 180^{\circ}\right)$ becomes strongest when $g=40 \mathrm{~mm}$ but is still lower by $20 \mathrm{~dB}$ than the co-polarization as shown in Figure 13(b). Similarly, the cross-polarization in $\pm y$-direction is not changed significantly.

The e-field distribution in the $x-z$ plane with a larger ground size of $g=40 \mathrm{~mm}$ is shown in Figure 14. Compared to Figure 9(b), the e-field is spread from the element edges with the extension of $g$. This effect of edge yields the efield directed to diagonal directions in $x-z$ plane; therefore, the diagonal e-field arrows have components in $z$ - and $x$ directions. The $z$-component of e-field around either the left or the right edge is directed to the opposite direction in the $z$-direction to the $z$-component around the other edge. This results in canceling out each other in the far field. Therefore, the vertical $z$-component to the ground is not radiated. On the other hand, with an increase in $g$, the $x$ components of e-field around both edges gradually get stronger at close positions of $<\lambda / 4$ to the ground plane. Therefore, the input impedance is reduced and gets difficult to be matched well to $50 \Omega$ as shown in Figure 12. For good impedance matching, the horizontal component should be reduced or the ring elements should not exist at a close position to the ground plane.

5.2. Effects of Air Interval between the Substrates. In the case of the antenna with the ground plane, $\left|S_{11}\right|$ characteristics and radiation patterns are not changed significantly compared to the structure without ground plane. In Figure 15, the impedance characteristics without ground plane are shown with a dotted line at the right side of the Smith Chart circumference. When the ground plane is installed, the kink 


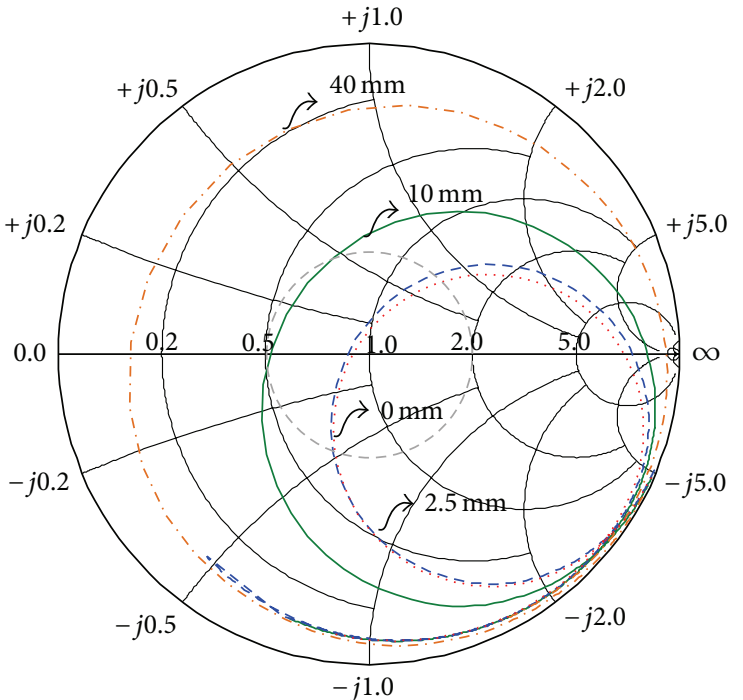

(a)

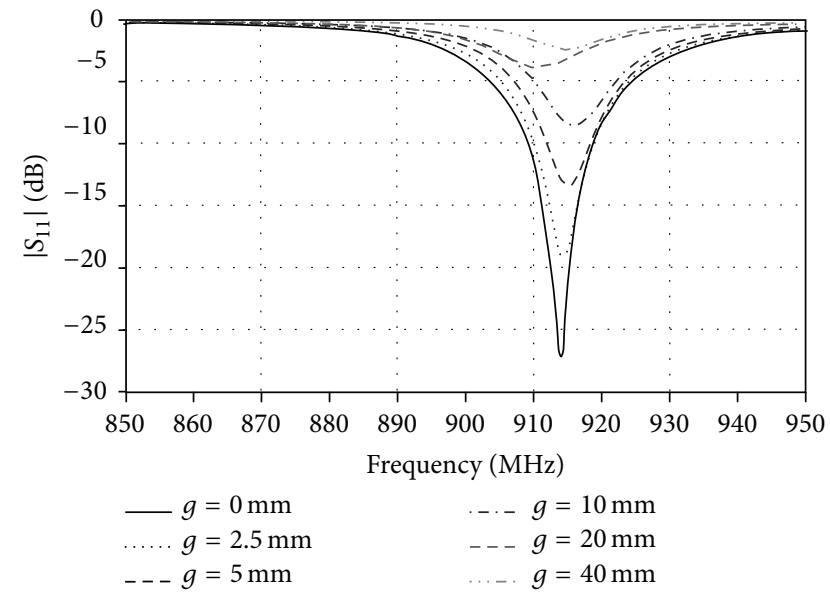

(b)

FIGURE 12: Simulated (a) input impedance characteristics and (b) $\left|S_{11}\right|$ characteristics as a function of $g$.

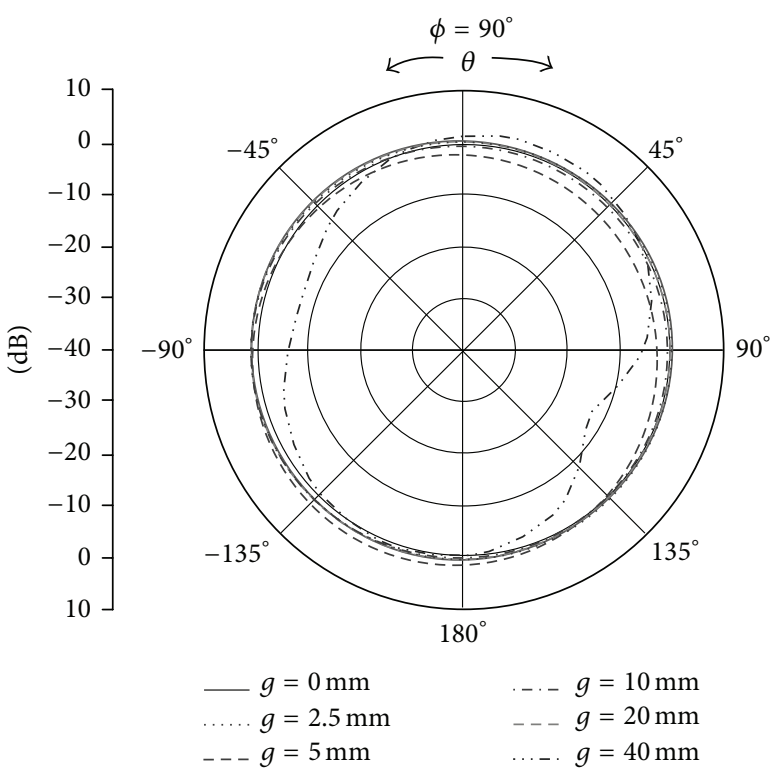

(a)

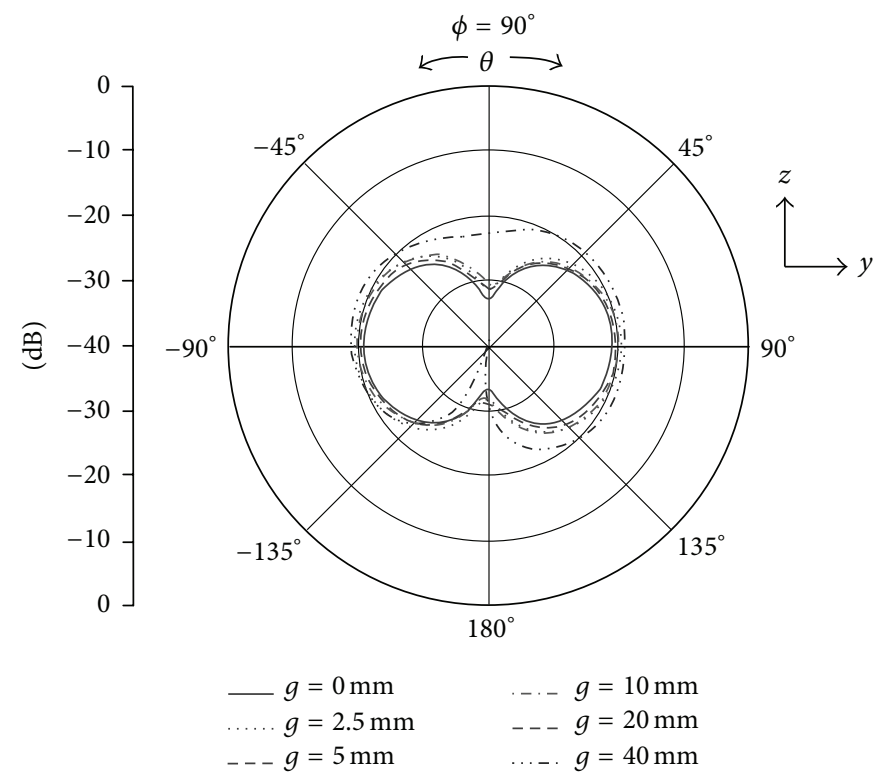

(b)

FIGURE 13: Simulated radiation patterns in the $y$ - $z$ plane at respective resonant frequencies as a function of $g(a)$ copolarization $\left(E_{\phi}\right)$, (b) cross-polarization $\left(E_{\theta}\right)$.

is shifted a little (solid line) along the circumference clockwise as shown in Figure 15. The shift is due to the two parallel feeding lines which have capacitive characteristics because, as shown with the dashed line in Figure 15, the impedance is close to the impedance with no ground plane when the parallel feeding lines are removed.

The effect of the air interval $s$ is discussed keeping $g=$ $0 \mathrm{~mm}$. The simulated input impedance characteristics are shown in Figure 16 as a function of $s$. When $s=0 \mathrm{~mm}$, the input impedance is too small resulting in the small kink around the circumference of the Smith Chart (dotted line). When the $s$ is increased from $3 \mathrm{~mm}$ to $13 \mathrm{~mm}$, the kink becomes larger to achieve VSWR $<2$ around the resonant frequency after being shifted clockwise along the circumference of the Smith Chart. Figure 17 shows the simulated radiation patterns in the $y-z$ plane at the respective resonant frequencies of $1489,887,913,924$, and $898 \mathrm{MHz}$ with an increase in $s$ from 0 to $13 \mathrm{~mm}$; however, the pattern is not changed significantly in the range from $s=3$ to $10 \mathrm{~mm}$. The co- and cross-polarizations are not significantly changed 


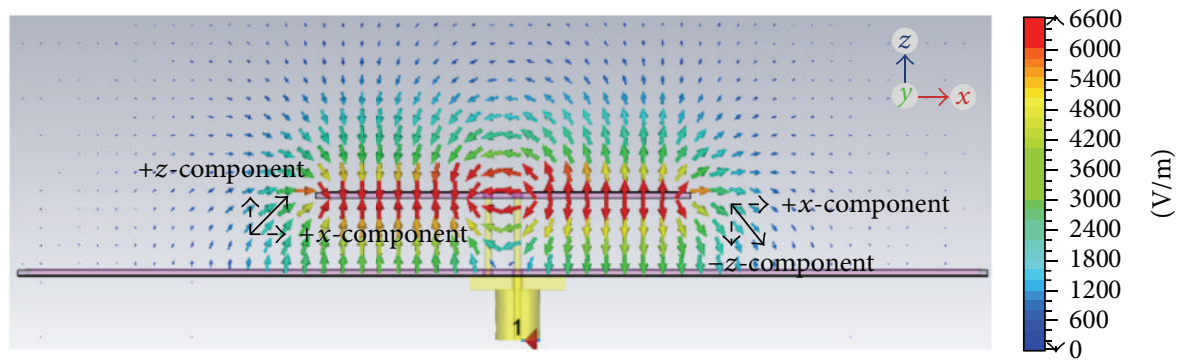

FIGURE 14: Electric field distribution in the $x-z$ plane at distances of $20 \mathrm{~mm}$ from the center of substrate along the $y$-axis at $\omega t=90^{\circ}$ for $g=40 \mathrm{~mm}$.

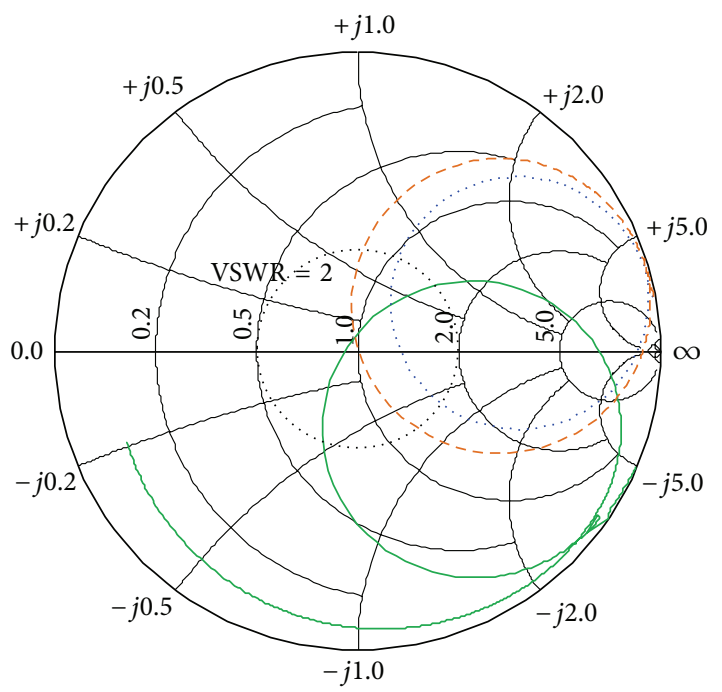

W... Without ground plane

- With ground plane

-- With ground plane, no parallel feed line

FigURE 15: Effect of the ground and the parallel feeding line on the simulated input impedance characteristics.

except when $s=0 \mathrm{~mm}$. As a result, the impedance is not sensitive to $s$ in the range of around 3 to $10 \mathrm{~mm}$, and the lowprofile structure is available in this range. This is because, as discussed in Section 4, the contribution to radiation of the efield from the interval is finally canceled out. Considering the e-field behavior in the interval, this behavior is also the reason why the impedance is not sensitive to the difference between the two structures with and without the ground plane as shown in Figure 15. However, when $s<3 \mathrm{~mm}$, the horizontal components of e-field get weaker because they are parallel to the ground plane; therefore, the impedance is affected by such a small $s$ value.

Finally, the effect of the environment surrounding the antenna is discussed. As far as $s \geq 3 \mathrm{~mm}$, the SRA with a small ground plane size of $g \leq 10 \mathrm{~mm}$ has similar performance to the antenna without ground plane. Hence, the characteristics of SRA are not sensitive to the small ground plane. This indicates that the SRA can be installed on compact handset applications keeping the same characteristics as that without

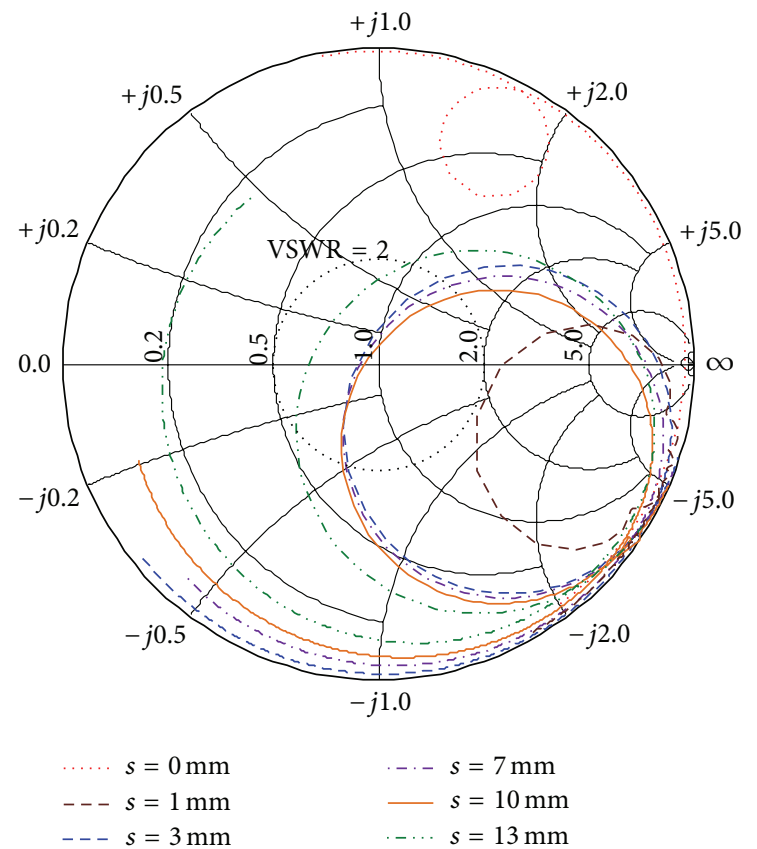

FIGURE 16: Simulated input impedance characteristics as a function of $s$.

ground plane. On the other hand, when $g>10 \mathrm{~mm}$ (large ground planes) and $s=10 \mathrm{~mm}$, the antenna has small impedance around the resonant frequency with a large kink in Smith Chart, as shown in Figure 12(a). A decrease in $s$ from $10 \mathrm{~mm}$ to $1 \mathrm{~mm}$ yields a smaller kink as shown in Figure 16. As shown in Figure 18 for $g=40 \mathrm{~mm}$ and $s=1 \mathrm{~mm}$, as an extreme example, the input impedance can be matched well to $50 \Omega$ with $\left|S_{11}\right|<-10 \mathrm{~dB}$. The use of a larger ground plane has also advantages such as reducing the effects of the backing material on the antenna characteristics; however we have to note that the bandwidth is narrower in this case.

\section{Conclusion}

This paper has proposed a compact and low-profile SRA with horizontally polarized omnidirectional radiation pattern. The 


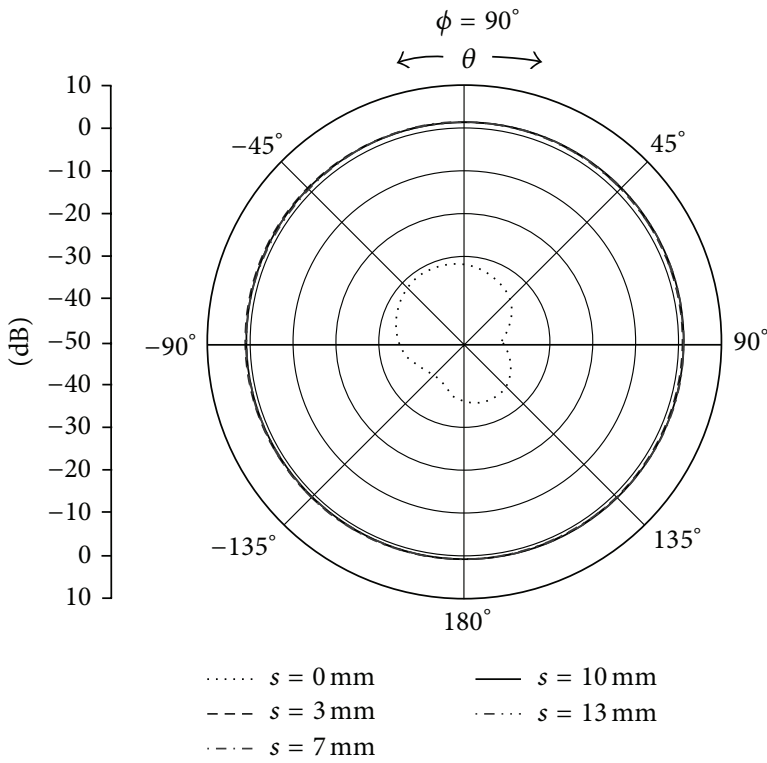

(a)

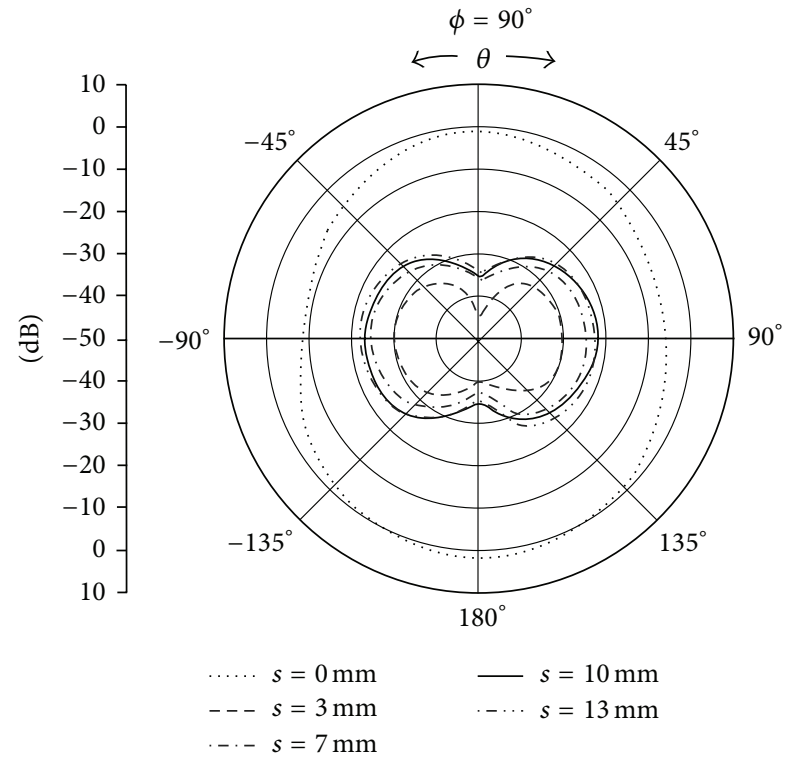

(b)

FIGURE 17: Simulated radiation patterns in the $y$ - $z$ plane at respective resonant frequencies as a function of $s(\mathrm{a})$ copolarization $\left(E_{\phi}\right)$ and $(\mathrm{b})$ cross-polarization $\left(E_{\theta}\right)$.

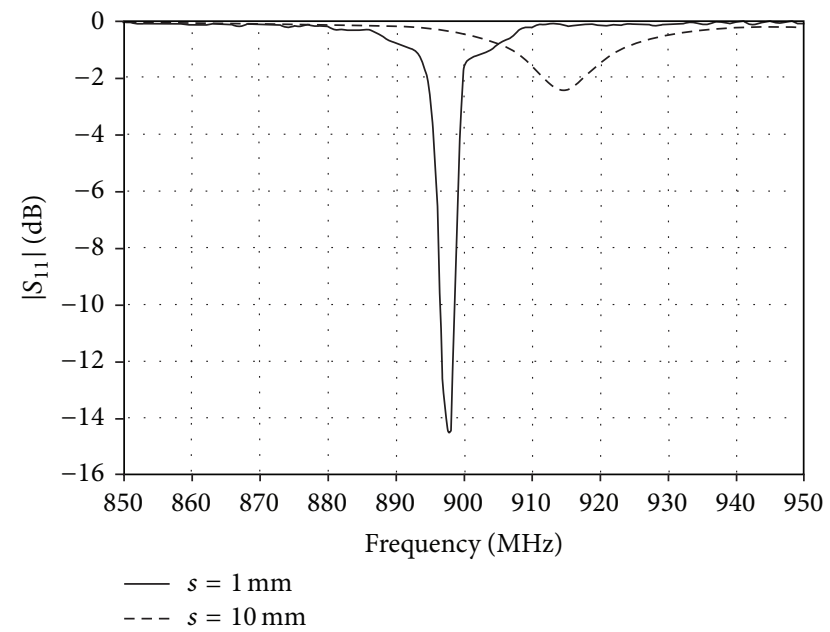

FIGURE 18: Simulated $\left|S_{11}\right|$ characteristics for a large ground plane with $g=40 \mathrm{~mm}$.

simulated and measured results show that the antenna can radiate horizontal polarization and has approximately omnidirectional radiation pattern. The mechanism for achieving the low-profile structure and obtaining horizontally polarized omnidirectional radiation pattern can be explained by observing the electric field distributions.

\section{Conflict of Interests}

The authors declare that there is no conflict of interests regarding the publication of this paper.

\section{Acknowledgment}

This work is supported by the Thailand Research Fund (TRF) through the Royal Golden Jubilee Ph.D. Program under Grant no. PHD/0324/2552.

\section{References}

[1] A. Alford and A. G. Kandoian, "Ultra-high frequency loop antenna," Transaction on the American Institute of Electrical Engineers (AIEE), vol. 59, no. 12, pp. 843-848, 1940.

[2] C.-C. Lin, L.-C. Kuo, and H.-R. Chuang, "A horizontally polarized omnidirectional printed antenna for WLAN applications," IEEE Transactions on Antennas and Propagation, vol. 54, no. 11, pp. 3551-3556, 2006.

[3] C.-H. Ahn, S.-W. Oh, and K. Chang, "A dual-frequency omnidirectional antenna for polarization diversity of MIMO and wireless communication applications," IEEE Antennas and Wireless Propagation Letters, vol. 8, pp. 966-969, 2009.

[4] Y. Yu, F. Jolani, and Z. Chen, "A wideband omnidirectional horizontally polarized antenna for $4 \mathrm{G}$ LTE applications," IEEE Antennas and Wireless Propagation Letters, vol. 12, pp. 686-689, 2013.

[5] K. Wei, Z. Zhang, Z. Feng, and M. F. Iskander, "A MNG-TL loop antenna array with horizontally polarized omnidirectional patterns," IEEE Transactions on Antennas and Propagation, vol. 60, no. 6, pp. 2702-2710, 2012.

[6] D. H. Lee, A. Chauraya, Y. Vardaxoglou, and W. S. Park, "A compact and low-profile tunable loop antenna integrated with inductors," IEEE Antennas and Wireless Propagation Letters, vol. 7, pp. 621-624, 2008.

[7] Y. Saito and T. Fukusako, "Low-profile and electrically small meander-line antenna using a capacitive feed structure," IEEE 
Antennas and Wireless Propagation Letters, vol. 11, pp. 1281-1284, 2012.

[8] J. Oh and K. Sarabandi, "Low profile vertically polarized omnidirectional wideband antenna with capacitively coupled parasitic elements," IEEE Transactions on Antennas and Propagation, vol. 62, no. 2, pp. 977-982, 2014.

[9] M. Kim and H. Arai, "Low-profile loop-shaped inverted-F wire antenna with dual-mode operation," IEEE Antennas and Wireless Propagation Letters, vol. 7, pp. 62-65, 2008.

[10] W. Hong and K. Sarabandi, "Low profile miniaturized planar antenna with omnidirectional vertically polarized radiation," IEEE Transactions on Antennas and Propagation, vol. 56, no. 6, pp. 1533-1540, 2008.

[11] J. Oh and K. Sarabandi, "Low profile, miniaturized, inductively coupled capacitively loaded monopole antenna," IEEE Transactions on Antennas and Propagation, vol. 60, no. 3, pp. 1206-1213, 2012.

[12] G. Breed, "Basic principles of electrically small antennas," Journal of High Frequency Electronics, pp. 50-53, 2007.

[13] C. A. Balanis, Antenna Theory: Analysis and Design, WileyInterscience, Hoboken, NJ, USA, 3rd edition, 2005.

[14] M. Polivka, A. Holub, M. Vyhnalik, and M. Svanda, "Impedance properties and radiation efficiency of electrically small double and triple split-ring antennas for UHF RFID applications," IEEE Antennas and Wireless Propagation Letters, vol. 12, pp. 221-224, 2013.

[15] Y. J. Kim and H. M. Lee, "Eelectrically small square loop antenna with a capacitive split ring resonator cover structure," Microwave and Optical Technology Letters, vol. 51, no. 3, pp. 831$835,2009$.

[16] S.-H. Lim, Y.-C. Oh, H. Lim, Y.-S. Lee, and N.-H. Myung, "Analysis and design of a UHF RFID tag antenna with a split ring resonator," in Proceedings of the International Workshop on Antenna Proceedings (iWAT '08), pp. 446-449, Chiba, Japan, March 2008.

[17] X. Quan and R. Li, "A broadband dual-polarized omnidirectional antenna for base stations," IEEE Transactions on Antennas and Propagation, vol. 61, no. 2, pp. 943-947, 2013.

[18] CST Microwave Studio, http://www.cst.com/.

[19] K. Lertsakwimarn, R. Suwalak, and C. Phongcharoenpanich, "A compact loop antenna with parasitic split ring for UHF RFID application," in Proceedings of the Progress in Electromagnetics Research Symposium (PIERS '13), pp. 219-222, Taipei, Taiwan, March 2013. 

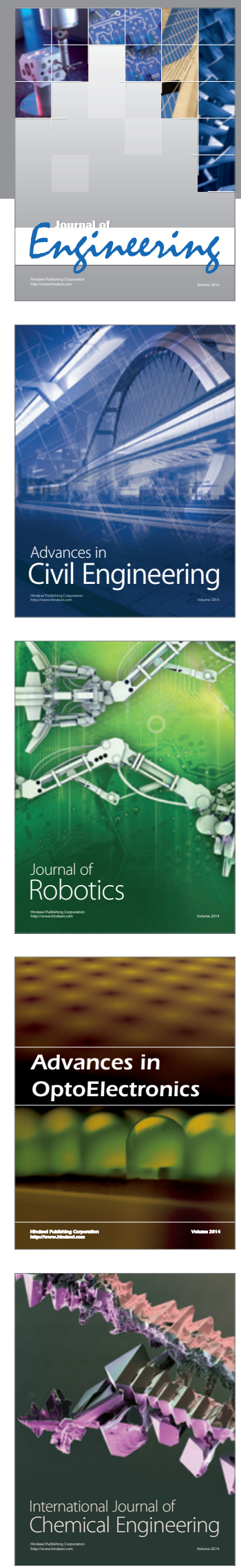

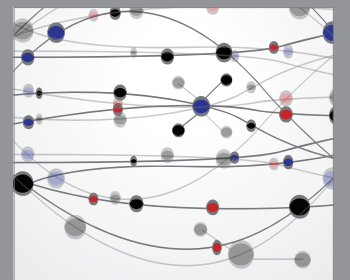

The Scientific World Journal
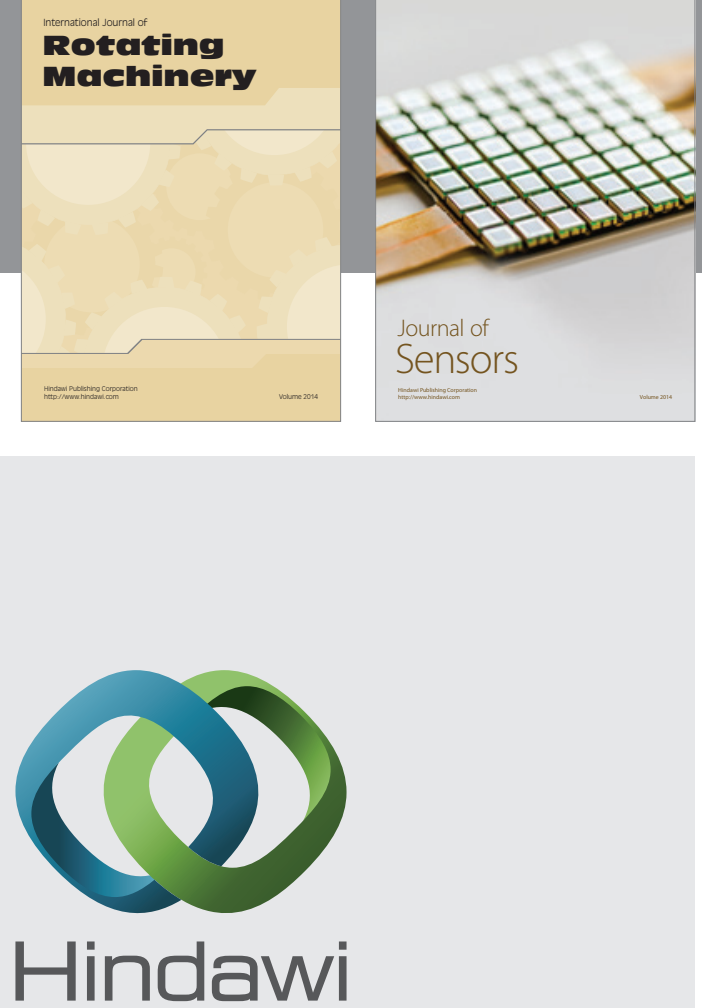

Submit your manuscripts at http://www.hindawi.com
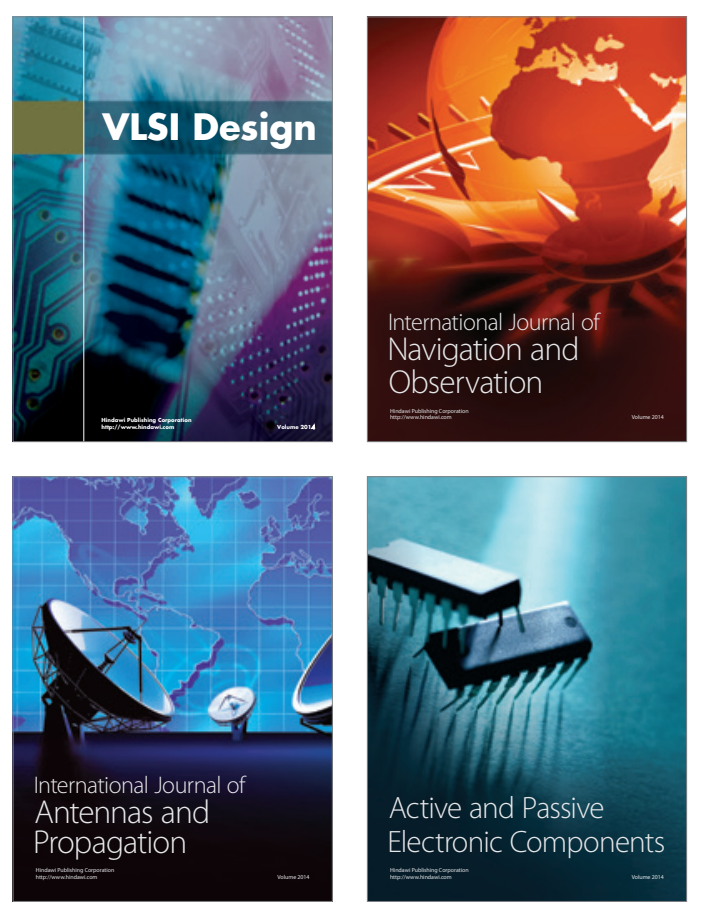
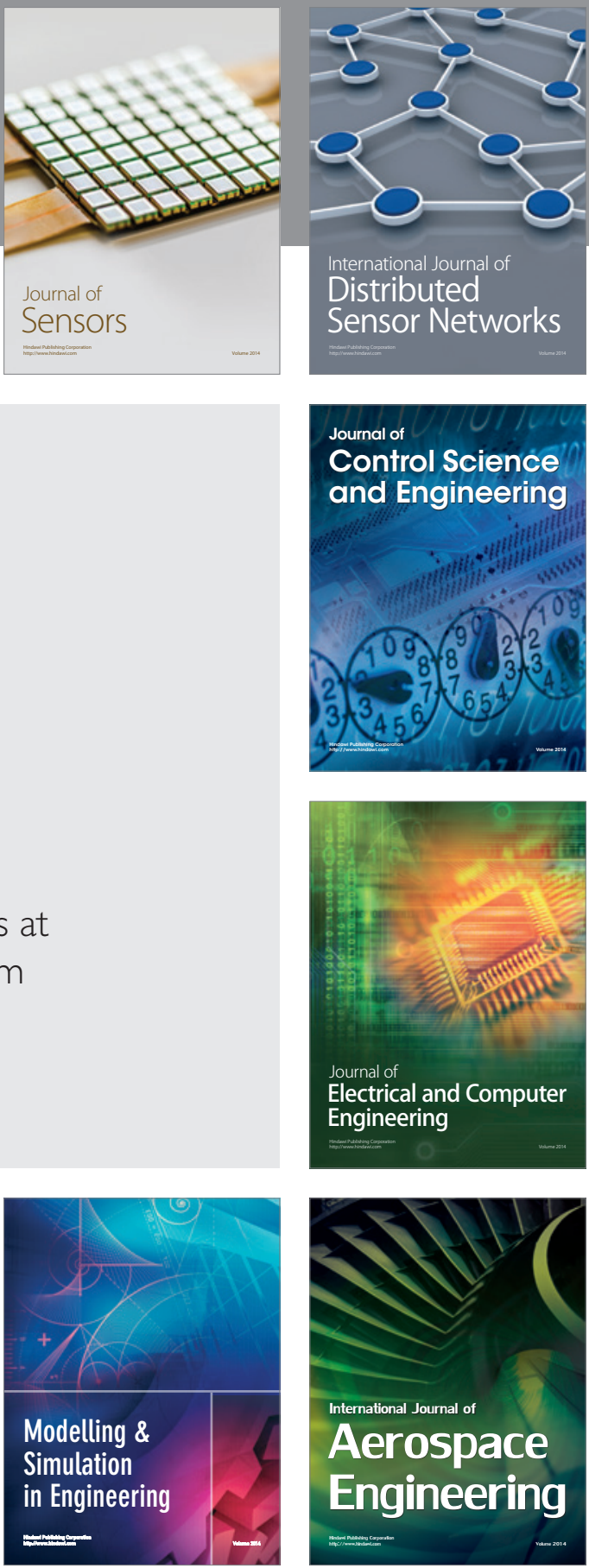

Journal of

Control Science

and Engineering
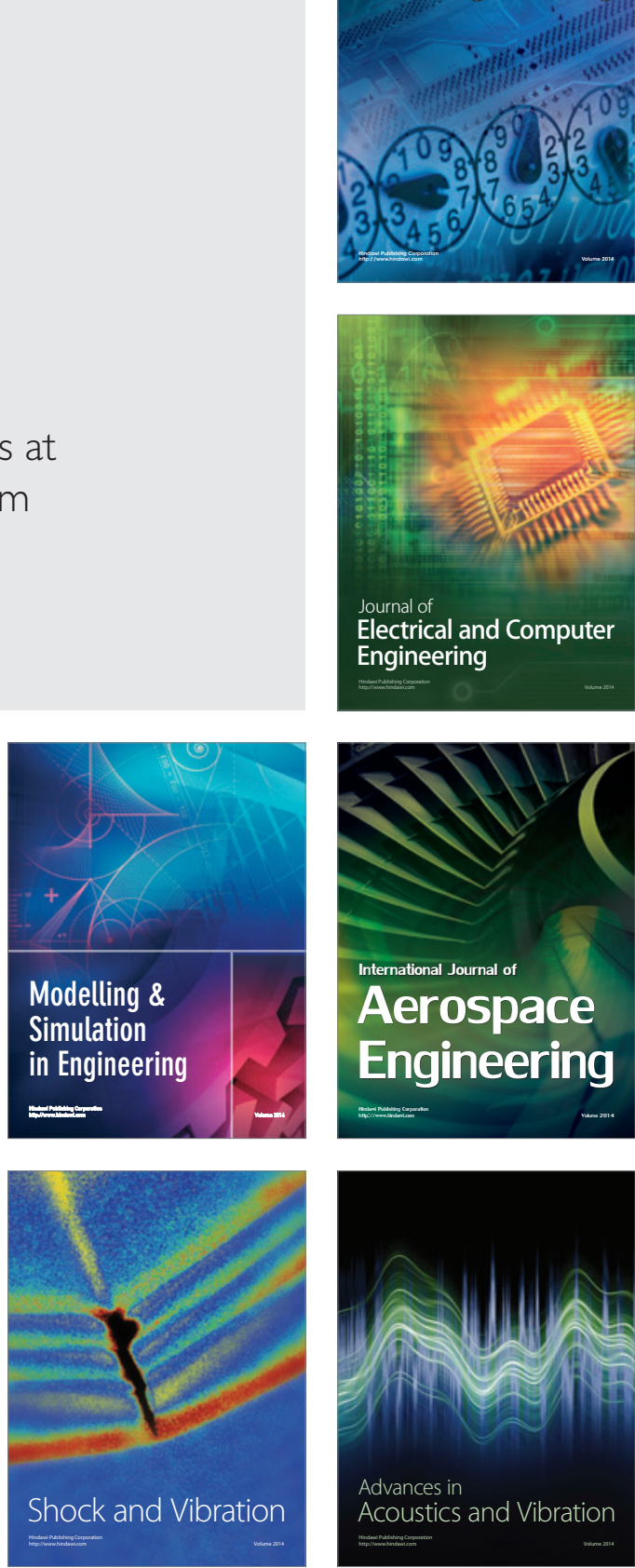